\title{
PRIMENA NERĐAJUĆIH ČELIKA U MOSTOGRADNJI
}

\author{
Miroslav T. Bešević ${ }^{1}$ \\ Tešanović Aniko ${ }^{2}$ \\ Kukaras Danijel ${ }^{3}$
}

UDK: 624.21 .014 .2

DOI: 10.14415/zbornikGFS22.011

Rezime: Nerđajući čelik je čelik, legiran u prvom redu hromom i niklom. Pojam "nerđajući čelik" označava više od 120 različitih legura sa antikorozivnim svojstvima. Nerđajući čelici poseduju niz izuzetnih osobina koje ih razlikuju od ostalih klasa čelika. U odnosu na ugljenični čelik ove osobine su između ostalog: nelegirano i asimetrično naponsko - deformacijsko ponašanje, anizotropija, izražen odgovor na proces hladnog oblikovanja, različit uticaj početnih imperfekcija, različite termičke osobine i stoga raspored zaostalih napona i njihov uticaj na konstrukciju. Čvrstoća materijala od nerđajućeg čelika, najčešće se uzima kao čvrstoća na granici od $0.2 \%$ dilatacija, u zavisnosti je od veličine plastične deformacije i temperature kojom je izložen tokom proizvodnje i upotrebe. U radu je data primena nerđajućih čelika u mostogradnji (tri mosta izvedena od nerđajućih čelika).

Ključne reči: Nerđajući čelik, mehaničke karakteristike, statički proračun, dimenzionisanje, EN-standardi, mostovi.

\section{UVOD}

Nerđajući čelik, ili kako ga često žargonski nazivaju rostfraj, inox, prohrom (nem. Rostfreier Stahl-nerđajući čelik) je čelik, legiran u prvom redu hromom i niklom. Inox je otkriven 1913. godine kada je engleski metalurg Harry Brearly radio na projektu poboljšavanja kvaliteta cevi pušaka. Slučajno je otkrio da dodavanjem hroma niskougljeničnom čeliku dolazi do otpornosti na oštećenja odnosno na koroziju. Reč INOX potiče od engleskog glagola inoxidizing, što znači sprečavanje oksidacije, rđe ili truljenja. Pod terminom nerđajući čelik kolokvijalno se podrazumeva „nekorozivni čelik". Nerđajući čelici su porodica materijala sa nizom jedinstvenih karakteristika. Hrom kao legirajući element formira transparentni i bezbojni zaštitni sloj na površini materijala, a ukoliko dođe do njegovog mehaničkog oštećenja, veoma brzo reaguje u prisustvu kiseonika iz vode ili vazduha, i stvara novi zaštitni film, tako da inox (prohrom) ne zahteva nikakvu dodatnu površinsku zaštitu protiv korozije. Ovde spadaju i čelici otporni na kiseline koji se odupiru pre svega elektrohemijskoj koroziji (organskim i neorganskim kiselinama, jedinjenjima azota, rastvorima soli - elektrolitima, agresivnim

\footnotetext{
${ }^{1}$ Prof. dr Miroslav T. Bešević, dipl inž građ., Građevinski fakultet Subotica, Kozaračka 2a, Univerzitet u Novom Sadu tel: 024-554-300, e -mail: miroslav.besevic@gmail.com

${ }^{2}$ Mr. Aniko Tešanović, Asistent ,dipl inž građ., Građevinski fakultet Subotica, Kozaračka 2a, Univerzitet u

Novom Sadu, e -mail: : misan.dag@gmail.com

${ }^{3}$ Doc.dr Kukaras Danijel ,dipl inž građ, e -mail: : dkukaras@gmail.com
} 
životnim namirnicama) i vatrootporni čelici koji se ne oksidišu na vazduhu i sagorelim gasovima $(\mathrm{CO}, \mathrm{CO} 2, \mathrm{SO} 2)$ na temperaturi preko $600^{\circ} \mathrm{C}$. Ovi čelici su definisani po SRPS C.B0.600. Čelici otporni na kiseline moraju sadržati više od $12 \% \mathrm{Cr}$, a vatrootporni čelici više od $6 \% \mathrm{Cr}$ i dodatke $\mathrm{Si}$ i $\mathrm{Al}$ radi sprečavanja dubinske korozije. Pojam „nerđajući čelik“ označava više od 120 različitih legura sa antikorozivnim svojstvima. Postizanje veće efikasnosti kod projektovanja elemenata od nerđajućeg čelika značajan je za popularizaciju ovog tipa konstrukcija kao i omogućavanje estetski elegantnije i za održavanje komotnije kao i izdržljivije konstrukcije. U poslednjim godinama može se videti povećana tražnja za visokolegiranim čelicima, uključujući i čelike visoke čvrstoće i nerđajuće čelike u konstruktivnoj primeni.

\section{a. Klasifikacija}

Visoko legirani nerđajući čelici mogu se podeliti u sledeće grupe u zavisnosti od svoje kristalne strukture:

- feritni nerđajući čelik,

- austenitski nerđajući čelik,

- martenzitni nerđajući čelik,

- feritno- austenitski nerđajući čelik (dupleks čelik)

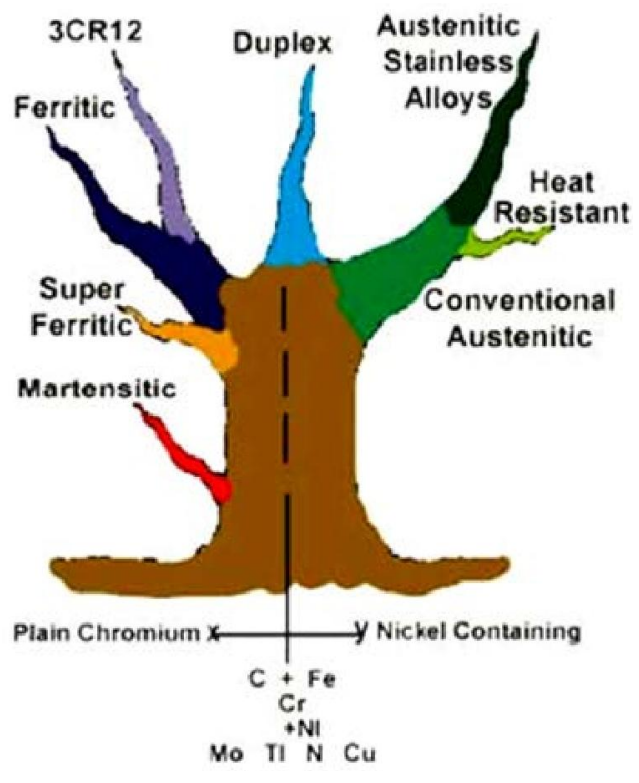

Slika1. Klasifikacija visoko legiranih nerđajućih čelika

Feritni nerđajući čelici su redom podeljeni u dve grupe:

- sa približno 11 do $13 \%$ hroma(Cr),

- sa približno $17 \%$ hroma $(\mathrm{Cr})$.

Zahvaljujući niskom sadržaju hroma 10.5 do $13 \%$ uz količinu ugljenika manju od $0.2 \%$ hromirani čelik se ukratko opisuje kao „,sporo korozioni”. Najčešće ih nazivaju „hromčelicima“ i ne mogu se podvrgavati ojačavanju. Oni su našli primenu u onim oblastima gde radni vek, sigurnst i malo održavanje su od najveće važnosti i gde ne postoje

\section{6 | ZBORNIK RADOVA 22 (2013)|}


posebni zahtevi o izgledu. Ovo je na primer slučaj kod kontejnera, vagona i konstrukcije vozila. [1], [5], [6]

\section{b. Austenitski nerđajući čelik}

Ovi čelici imaju visok procenat hroma, $15-26 \%$ uz 5-25\% nikla. Otpornost na kiseline i agresivne materije povećava se dodavanjem $2-6 \%$ molibdena. U ovoj grupi čelika su i takozvani „stabilizovani“ nerđajući čelici, koji pored hroma, nikla i molibdena, sadrže na primer titanijum. Dodavanje titanijuma omogućava bolje ponašanje nerđajućih čelika prilikom zavarivanja, jer sprečava pojavu nepoželjnih hrom-karbida u šavu, koji se takođe navodi kao „hrom-nikl“ čelik, sa sadržajem Ni od preko $8 \%$ a često sadrže i molibden koja je najbolja kombinaija u odnosu na mogućnost obrade, korozionu otpornost i mehaničke karakteristike. Predstavljaju najvažniju grupu nerđajućih čelika i zbog tog razloga preporučuju se za najširi opseg upotrebe $u$ oblastima, gde se koriste $u$ agresivnim sredinama, kao na primer u slučaju kontakta sa morskom vodom koja sadrži hlor, u hemijskoj ili prehrambenoj industriji. Za razliku od martenzitnih, austenitni nerđajući čelici ne podvrgavaju se ojačavanju temperaturom. Zahvaljujući svojim osobinama, veoma se lako deformišu „na hladno“.

\section{c. Martenzitni nerđajući čelik}

Martenzitni nerđajući čelik sa $12-18 \%$ Cr i uz učešće ugljenika od $0.2-1 \%$ su austenitski na temperaturama preko $950-1050{ }^{\circ} \mathrm{C}$. Količina ugljenika mora da bude takva da dozvoljava termičku obradu - temperovanje, što popravlja dinamičke karakteristike čelika. Brzo hlađenje (suzbijanje) vodi do formiranja martenzitne strukture. Ova struktura poseduje visoku tvrdoću posebno u kaljenom stanju kada se dodatno povećava sa povećanjem sadržaja ugljenika-C. Ovakvi čelici se koriste npr. u proizvodnji oštrica, noževa ili makaza. Preduslov za dovoljnu korozionu otpornost je odgovarajuća površinska obrada koja se može postići na primer pomoću brušenja.

\section{d. Feritno austenitski nerđajući čelik}

Feritno austenitski nerđajući čelik koje se često navodi kao dupleks čelik zahvaljujući svojoj dvokomponentnoj strukturi. Visoka rastegljivost sa istovremenim poboljšanjima korozione otpornosti omogućavaju ovim čelicima da se koriste posebno u oblasti tehnologije podupirača.

\section{e. Čelici otporni na habanje}

Procenjuje se da oko 50-80\% svih otkaza mašina i opreme nastaje zbog habanja, a ostalo usled zamora materijala, preopterećenja ili grubog narušavanja radnih uslova. Otpornost čelika prema habanju uslovljena je hemijskim sastavom (uglavnom visok sadržaj C i Mn) i strukturom, ali i vrstama habanja koje mogu biti:

Adheziono, abraziono, eroziono, kavitaciono, zamorno, vibraciono, Abrazivno habanje može nastati dejstvom:

- udarnih sila (kašike bagera na kamenitom terenu, drobilice za kamen) i

- $\quad$ rasutog materijala (rude, šljaka, pesak, cement, pepeo, žitarice i dr.). 
Za delove izložene habanju udarnog tipa primenjuje se manganski austenitni čelik Č3160 poznat pod nazivom Hadfield-ov čelik $(13 \% \mathrm{Mn}, 1.2 \% \mathrm{C})$. Otporan je na abrazivno habanje samo ako se pri radu jako plastično deformiše. Za abrazivno habanje rasutim materijalima bitna je što veća tvrdoća pa se koriste niskolegirani poboljšani čelici i alatni ledeburitni čelici. Upotrebljavaju se za čeljusti drobilica za kamen, kugle mlinova za drobljenje ruda, a najviše za železničke i tramvajske šine i skretnice.

\section{f. Mehaničke osobine nerđajućih čelika}

Nerđajući čelici poseduju niz izuzetnih osobina koje ih razlikuju od ostalih klasa čelika, u odnosu na ugljenični čelik kao što je: nelegirano i asimetrično naponsko deformacijsko ponašanje, anizotropiju, izražen odgovor na proces hladnog oblikovanja, različit uticaj početnih imperfekcija i različite termičke osobine, stoga raspored zaostalih napona i njihov uticaj na konstrukciju. Ništa manje neobična osobina je nemagnetičnost austenitnih nerđajućih čelika koju duguju u prvom redu niklu kao legirajućem elementu, koji stabilizuje visokotemperaturnu, nemagnetičnu, površinski centriranu kubnu modifikaciju železa-austenit. Elementi od nerđajućeg čelika ne mogu biti zasnovani na istraživanjima na ugljeničnom čeliku. Za razliku od preseka od ugljeničnih čelika koji ima jasno izraženu granicu elastičnosti / granica razvlačenja / nivo tečenja i umereno očvršćavanje, nerđajući čelik ima zaobljenu krivu napon - deformacija uz značajno ojačanje dilatacija u nedostatku jasno definisane tačke tečenja. Napon $\sigma 0.2$ je usvojeni napon $0.2 \%$ iz granice proporcionalnosti definisane naponom od $0.01 \%$ od plastične dilatacije. Dodatne glavne razlike u obliku naponsko - deformacijskog odgovora između preseka od nerđajućeg čelika su praćene još i različitim tehničkim osobinama, uključujući specifičnu toplotu, termičku provodljivost, termičko širenje. Sve ovo ima uticaj na formiranje zaostalih napona. Specifična toplota nerđajućeg čelika je oko $500 \mathrm{~J} / \mathrm{kgK}$, dok ugljenični čelik ima ovu vrednost oko $600 \mathrm{~J} / \mathrm{kgK}$. Materijal sa nižim specifičnom toplotom ima brže zagrevanje. Za temperature ispod $1000^{\circ} \mathrm{C}$ termička provodljivost nerđajućih čelika je niža od ugljeničkih čelika, na nižim temperaturama ova razlika je značajna, dok preko $700^{\circ} \mathrm{C}$ razlika je mala. Koeficijent termičkog širenja nerđajućeg čelika je i do $50 \%$ veća od ugljeničnog čelika što može imati za posledicu veću deformaciju materijala tokom unosa toplote i više zaostale napone. Na slici br.2 daje se dijagram $\sigma / \varepsilon$ za nerđajući čelik, a na slici br.3 prikazani su uporedno dijagrami $\sigma / \varepsilon$ ugljeničnih i nerđajućih čelika.

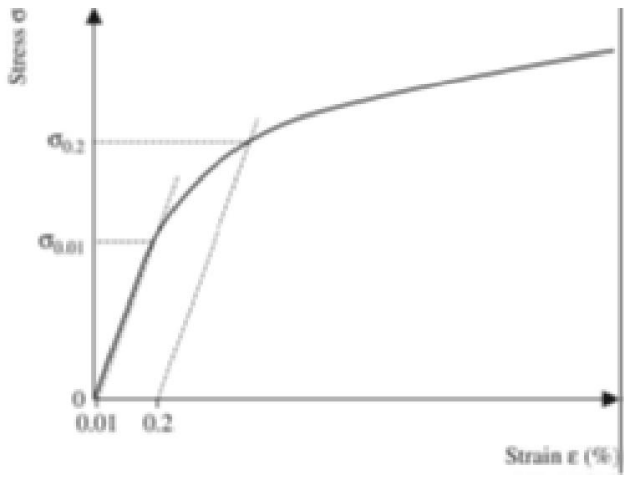

Slika 2. Dijagram $\sigma / \varepsilon$ za nerđajući čelik

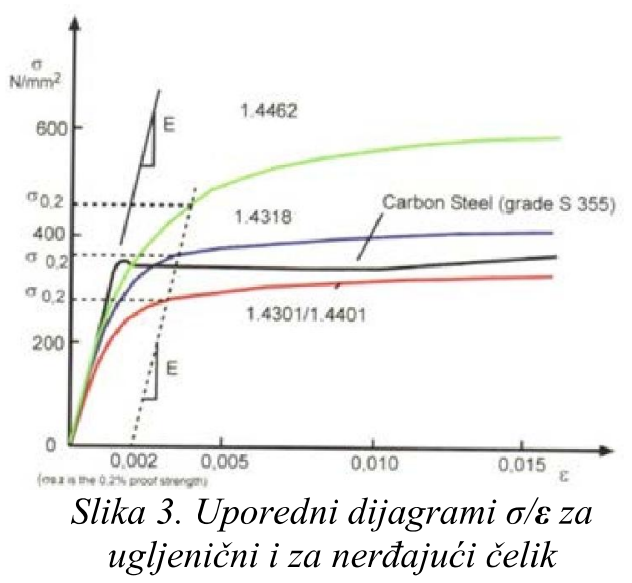

118 | ZBORNIK RADOVA 22 (2013) | 
Naponsko- deformacijski odgovor preseka od nerđajućeg čelika potiče još iz 1943, najnovije verzije su prikazane na slici br.3.

Dodatne glavne razlike u obliku naponsko-deformacijskog odgovora između preseka od nerđajućeg čelika su praćene još i različitim tehničkim osobinama, uključujući specifičnu toplotu, termičku provodljivost, termičko širenje. [2]

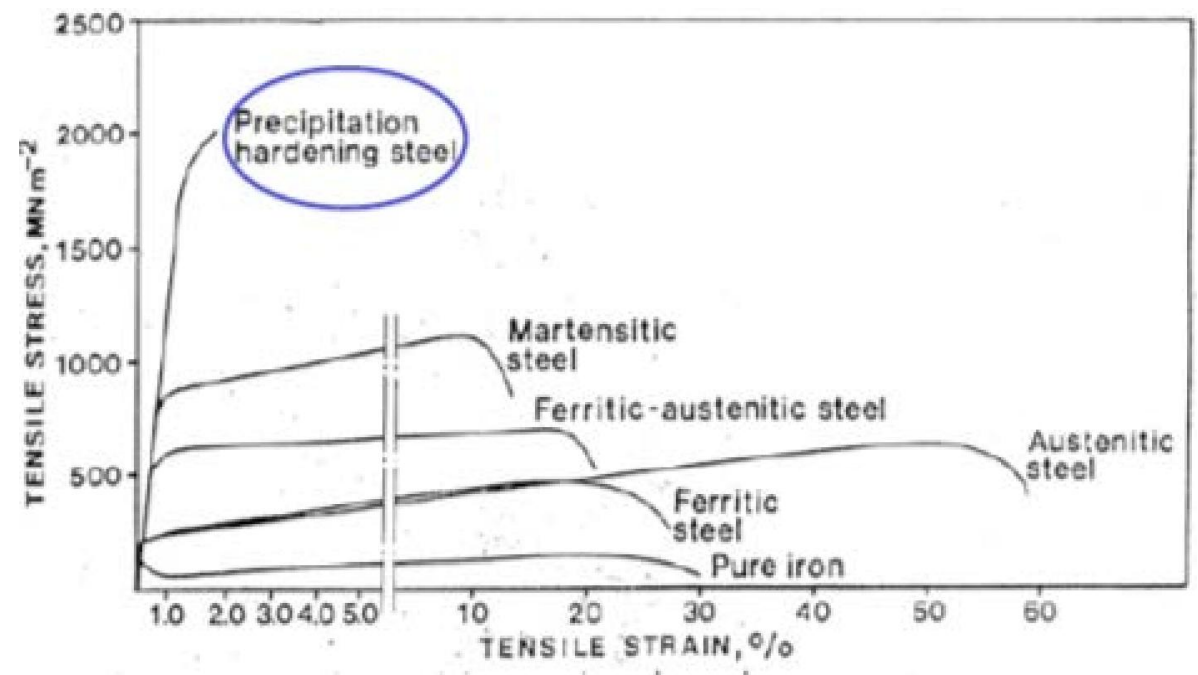

Slika 4. Uporedni dijagrami $\sigma / \varepsilon$ za vrste nerđajuih i čelika

Tabela 1. Standardni nerđajućoi čelici i njihov hemijski sastav

\begin{tabular}{|c|c|c|c|c|c|c|c|c|c|}
\hline & $\begin{array}{l}\text { Oznaka } \\
\text { materijala }\end{array}$ & Materijal br. & $\begin{array}{l}\mathrm{C} \\
\%\end{array}$ & $\begin{array}{l}\mathrm{Si} \\
<\%\end{array}$ & $\begin{array}{l}\mathrm{Mn} \\
\% \%\end{array}$ & $\begin{array}{l}\mathrm{Cr} \\
\% \\
\end{array}$ & $\begin{array}{c}\text { Mo } \\
\%\end{array}$ & $\begin{array}{l}\mathrm{Ni} \\
\%\end{array}$ & $\begin{array}{c}\text { Altri } \\
\%\end{array}$ \\
\hline \multirow{3}{*}{$\Delta 2$} & X $5 \mathrm{Cr} \mathrm{Ni} 1810$ & 1.4301 & $<0,07$ & 1,0 & 2,0 & $\begin{array}{l}17,0 \\
20,0\end{array}$ & - & $\begin{array}{c}8,5 \\
\prod_{10,0}\end{array}$ & - \\
\hline & X $2 \mathrm{Cr} \mathrm{Ni} 1811$ & 1.4306 & $<0,03$ & 1,0 & 2,0 & $\begin{array}{r}17,0 \\
20,0 \\
\end{array}$ & - & $\begin{array}{c}10 \\
\prod \\
12,5\end{array}$ & - \\
\hline & X $8 \mathrm{CrNi} 19 / 10$ & 1.4303 & $<0,07$ & 1,0 & 2,0 & $\begin{array}{l}17,0 \\
20,0\end{array}$ & - & $\begin{array}{c}10,5 \\
\Pi \\
12 \\
\end{array}$ & - \\
\hline & X $6 \mathrm{CrNiTi} 1811$ & 1.4541 & $<0,10$ & 1,0 & 2,0 & $\begin{array}{l}17,0 \\
19,0\end{array}$ & - & $\begin{array}{c}9,0 \\
\prod_{11,5}\end{array}$ & $T i \geq 5 X \% C$ \\
\hline \multirow{2}{*}{$\Delta 4$} & $\times 5 \mathrm{CrNiMo} 1712$ & 1.4401 & $<0,07$ & 1,0 & 2,0 & $\begin{array}{l}16,5 \\
18,5 \\
\end{array}$ & $2,02,5$ & $\begin{array}{c}10,5 \\
\prod_{13,5} \\
\end{array}$ & - \\
\hline & X $2 \mathrm{Cr}$ Ni Mo 1712 & 1.4404 & $<0,03$ & 1,0 & 2,0 & $\begin{array}{l}16,5 \\
18,5\end{array}$ & $2,02,5$ & $\begin{array}{l}11 \\
11 \\
14\end{array}$ & - \\
\hline & X $6 \mathrm{Cr} \mathrm{Ni} \mathrm{Mo} \mathrm{Ti} 1712$ & 1.4571 & $<0,10$ & 1,0 & 2,0 & $\begin{array}{l}16,5 \\
18,5\end{array}$ & $2,02,5$ & $\begin{array}{c}10,5 \\
\prod_{13,5}\end{array}$ & $T i \geq 5 X \% C$ \\
\hline
\end{tabular}

Zbog visokog afiniteta ka stvaranju karbida hrom difundije u oblast granice zrna gde stvara krti hrom karbid. Pošto antikorozivno svojstvo nerdjajućih čelika u prvom redu obezbeđuje hrom kao legirajući element, osiromašenje osnove hromom uzrokuje manju 
otpornost na interkristalnu koroziju. Da bi se sprečilo izdvajanje neželjenog hrom karbida dodaju se Ni ili Ti koji imaju veći afinitet prema ugleniku od hroma. Na taj način stabilizirani čisto feritni čelici sa 12 do $18 \%$ hroma kao X2CrTi12(1.4512), X2CrTi17(1.4510) predstavljaju danas najvažniju grupu nerđajućih čelika sa širokom upotrebom. Feritni valjani nerđajući čelici sadrže $10.5-27 \% \mathrm{Cr}(18 \mathrm{Cr}-2 \mathrm{Mo}, 26 \mathrm{Cr}-1 \mathrm{Mo}$, 29Cr- 4Mo i 29Cr-4Mo-2Ni). Sadrže manje ugljenika, a više hroma nego martenzitni čelici pa se ne mogu kaliti, već ojačavaju samo preradom na hladno. Feritni nerđajući čelici su magnetični, a ako sadrže dovoljno $\mathrm{Cr}$ i Mo zadržavaju svoju osnovnu mikrostrukturu sve do tačke topljenja. U žarenom stanju jačina na kidanje ovih čelika za $50 \%$ nadmašuje ugljenične čelike

\section{STONECUTTERS BRIDGE TOWERS (Most u Hong Kongu)}

Most u Hong Kongu je sistema kosih kablova ukupne dužine 1596 metara sa glavnim rasponom od $\mathrm{l}=1018 \mathrm{~m}$, a otvoren je krajem 2009. Najupečatljivije karakteristike mosta su piloni-stubovi. Ovi stubovi se sužavaju na 295 m nadmorske visine, dok su donji delovi izvedeni od armiranog betona. Gornjadeo stuba dužine $115 \mathrm{~m}$ su spregnutekompozitne sekcije sa spoljnom oblogom od nerđajućeg čelika i armiranog betonskog jezgra. Na slikama br.5 i br.6 se prikazje izglrd mosta i detalj sekcije veze kablova i stuba.

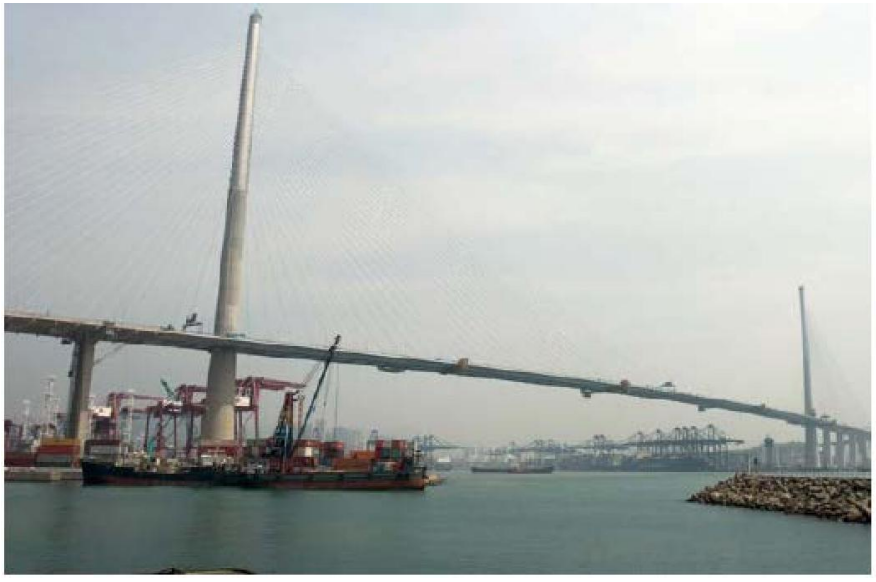

Slika 5: Opšti izgled mosta

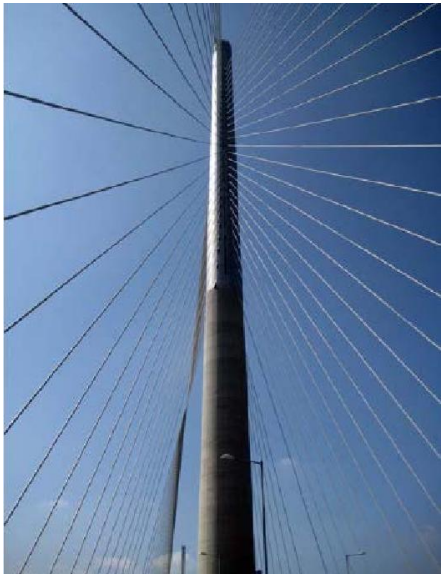

Slika 6. Veza kablova $i$ polona-stuba mosta

\subsection{Izbor materijala}

Projektovani životni vek mosta je 120 godina. Na gornjim delovima stubova mosta zbog oštre i zagađene životne sredine potreban je koroziono izdržljiv materijal. Nakon izgradnje mosta, održavanje stubobva će biti izuzetno teško, zbog živog saobraćaja ispod. Nerđajući čelik je izabran za oblogua gornjeg dela stuba, zbog svoje korozione otpornosti, a takođe i zbog atraktivnog izgleda. Ugljenični čelik bi zahtevalo zaštitne premaze koji bi morali da se menjaju nakon perioda cca od 25-30 godina. Dupleks čelik 
1.4462 (S32205) je izabran jer ima veliku granicu razvlačenja. $(\sigma y=460 \mathrm{~N} / \mathrm{mm} 2)$ uz dobru otpornost na koroziju i tolerancije pri završnoj obradi.

\subsection{Proračun konstrukcije mosta}

Prvi projekat konstrukcije za gornji deo stuba-pilona mosta( $115 \mathrm{~m})$ je bio usvojen ceo od čeličnih sekcija. Međutim, kružni piloni su kao što je poznato osetljivi na vrtložne vibracije. Analiza je pokazala da su se frekvencije bočnih oscilacija na vrhu pilona poklopile sa prirodnim frekvencijama oslanjanja kablova. Da bi se to sprečilo, usvojen je i dimenzionisan gornji deo pilona kao spregnuta konstrukcija sa nerđajućim čelikom u vidu obloge, oko armiranog betonskog prstenastog jezgra, okruženog čeličnim kablova kiji su sidreni u kutije. Ovaj konstruktivni oblik pokazao bolji odgovor, zbog svoje veće mase, krutosti i prigušenja. Obloga pilona se sastoji od 32 segmenata od nerđajućeg čelika (slika 7) svaki debljine od $20 \mathrm{~mm}$, od toplovaljanih ploča i različitih visina od 5,6 m do 3,2 m. Prečnik kružnog pilona se sužava od $10,9 \mathrm{~m}$ do $7,2 \mathrm{~m}$ a debljina betonskog i zida se smanjenje sa $1,4 \mathrm{~m}$ na $0,8 \mathrm{~m}$. Niža tri segmenta kosim kablovima su usidreni u armirano betonski donji delo pilona. Iznad toga posavljeni sui 25 čelične anker kutije u koje se ugrađuju preostalih 25 kompleta kosih kablova. Na vrhu svakog pilona, prostor ostaje za buduću ugradnju amortizera klatna mase, koje trebaju da budu u obavezi da ublaže vibracije pilona.Na slici br.8 prikazan je način montaže mosta.

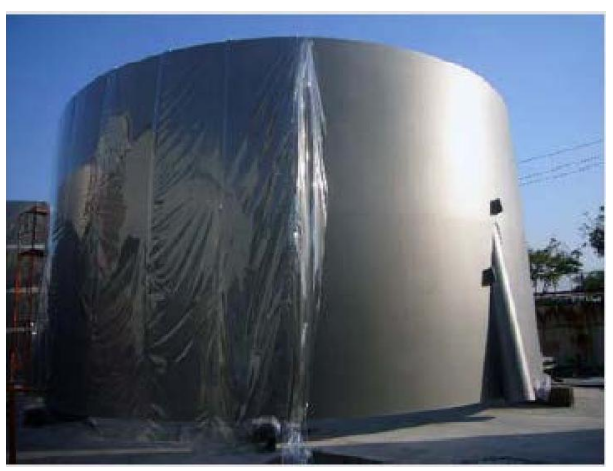

Slika 7: Segment od nerđajućeg čelika

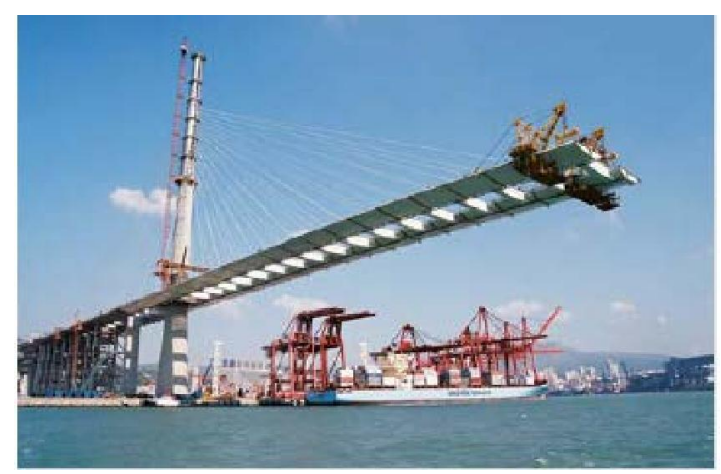

Slika 8: montaža mostovske konstrukcije

Da bi se olakšalo dizanje, svaki od nerđajućeg segmenata je proizveden od dve polovine, sa $25 \mathrm{~mm}$ debljom prirubnicom. Vertikalni spojevi od dupleks nerđajućeg čelika su spajani zavrtnjima visoke čvrstoće M22, kako bi se obezbediloveliko trenje između spojnih elemenata. Kontaktna površina za povezivanje ploča morala je da ima poseban tretman, kako bi se osiguralo da je koeficijent trenja $\mu>0,2$. Zavrtnji su prethodno prednapregnuti silom prednaprezanja da postigne nosivost od $165 \mathrm{kN}$. Nije bilo dozvoljeno proklizanje veze. Horizontalni spojevi su bili efikasni u prenosu vertikalne komponente sile. Pošto je visina pojedinih segmenata od nerđajućeg čelika mala u odnosu na ukupni prečnik segmenta, pojedini segmenti efikasno deluju kao odvojeni horizontalni obruči. Dakle, segmenti od nerđajućeg čelika, su pretpostavljali, da primaju samo direktne pritiske vertikalno ili horizontalno, a ne smicanja i savijanje. Izrada je ostvarena tako što su za tipične segmente, korišćene četiri ravne ploče koje su 
prvo zavarivane $\mathrm{u}$ horizontalnoj ravni, a zatim se okretale u vertikalan položaj. Međutim, za prva četiri segmenta obloge, koji suvisine $5,6 \mathrm{~m}$, ploče su savijane pre zavarivanja, zbog širine ograničenja mašine za savijanja. Montaža obloge od nerđajućeg čelika i kutija za sidrenje kablova, su korišćeni kao stalna oplata za betoniranje. Montaža obloge i delova kutija za sidrenje kablova napredovala je dva puna ciklusa pre betoniranja.

\section{CALA GALDANA BRIDGE ( Kala Galdana most)}

Kala Galdana most prelazi reku u Algendar Menorka. Ima panoramski pogled na popularne plaže sa rasponom od mosta $1=55$ metara, a ukupna širine mosta je $13 \mathrm{~m}$. Glavna konstrukcija mosta je u potpunosti izgrađena od nerđajućeg čelika i obuhvata dva paralelna uzdužna i poprečna nosača koji prihvataju kolovoznu tablu. Oslonci su u obliku potprnih armiranobetonskih krilnih zidova na svakom kraju a fundirani su na masivnim temeljima oslonjenih na šipove. Most je otvoren 2005 i bio je prvi drumski most od nerđajućeg čelika u Evropi.

\section{g. Izbor materijala}

Postojeći armirano-betonski most preko Algendar reke bio je izgrađen pre 30 godina, ali usled agresivne morske sredine došlo je do značajnog oštećenja konstrukcije. Nakon sanacije konstrukcije potpornih zidova, odlučeno je da se zameni most. Uslov zamene je bio potreban veoma izdržljiv materijal za konstrukciju mosta, kako bi se postigao dug život mosta, sa niskim zahtevima za održavanjem. Zbog značaja prihoda od turizma za ovu oblast, usvojen je materijal koji se uklapa sa prirodnim okruženjem a izaziva minimalno remećenje tokom izgradnje, što je sve bilo definisano projektnim zadatkom. Analizirane su različite vrste ugljeničnih čelika čelika kao kvalitetnii nerđajući čelici. Tabela 3 upoređuje njihova mehanička svojstva . Nerđajući dupleks čelik 1.4462 (S32205) je na kraju izabran, zato što ima visoku granicu razvlačenja (koja prelazi iznos od većine ugljeničnih čelika), dobra duktilnost i izdržljiv u morskim sredinama. Nakon izgradnje, kontrola kvaliteta i sva potrebna ispitivanja su izvedena na konstrukciju mosta. Ova merenja su pokazali da su minimalne vrednosti premašile značajnoom projekovane vrednosti(takođe prikazano u tabeli 2).

Tabela 2. Mehaničke osobine čelika matraju za Cala Galdana mosta

\begin{tabular}{|l|c|c|l|}
\hline Vrsta čelika & $\begin{array}{c}f y(0,2 \%) \\
(\mathrm{N} / \mathrm{mm} 2)\end{array}$ & $\begin{array}{l}f u \text { (zateznačvrstoća) } \\
(\mathrm{N} / \mathrm{mm} 2)\end{array}$ & Izduženje (\%) \\
\hline $\begin{array}{c}\text { Ugljenični čelik } \\
(\mathrm{S} 355)\end{array}$ & 355 & 510 & 15 \\
\hline $\begin{array}{l}\text { Austentik nerđajući } \\
\text { čelik(1.4404/S31603) }\end{array}$ & 220 & 530 & 40 \\
\hline $\begin{array}{c}\text { Dupleks nerđajući } \\
(1.4462 / \mathrm{S} 32205)- \\
\text { atest }\end{array}$ & 460 & 640 & 25 \\
\hline $\begin{array}{c}\text { Dupleks nerđajući } \\
(1.4462 / S 32205)- \\
\text { izmereno }\end{array}$ & 535 & 767 & 35 \\
\hline
\end{tabular}




\section{h. Projektovanje}

Osnova za projektovanje konstrukcije mosta je u tom trenutku nacrt Eurocode 3, deo 1.4 i druge evropske smernice i propisi. Preporuke za proveru otpornosti na granična stanja nosivosti i granični kriterijumi za deformacije i vibracije obuhvaćeni su i pokriveni od strane španskog standarda za izradu čeličnih mostova. Konstrukcija mosta je u vidu dva glavna paralelna luka raspona $45 \mathrm{~m}$, sa maksimalnom visinom od $6 \mathrm{~m}$ iznad nivoa vode. Lukovma su priključeni dva uzdužna nosača (grede) celom dužinom mosta. Na uzdužne grede se oslanjaju poprečni nosači koje na koje se oslanja kolovozna tablaploča. Sprezanje čelične konstrukcije mosta i armirano betonske kolovozne ploče je ostvareno moždanicimakoji su zavareni za gornji pojas poprečnih nosača. Na sledećim slikama se prikazuju izgledi mosta.

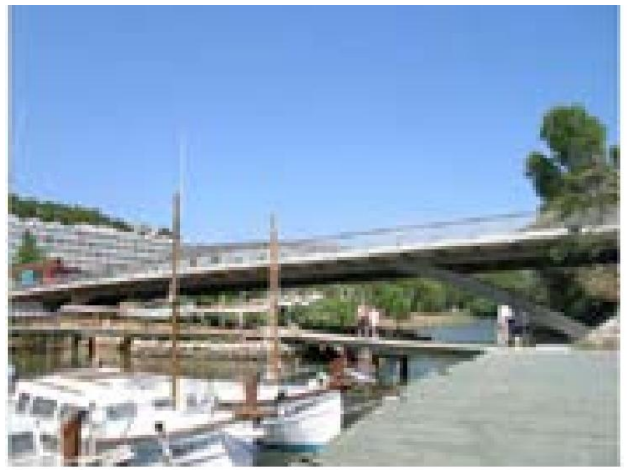

Slika 9. Glavni izgled mosta

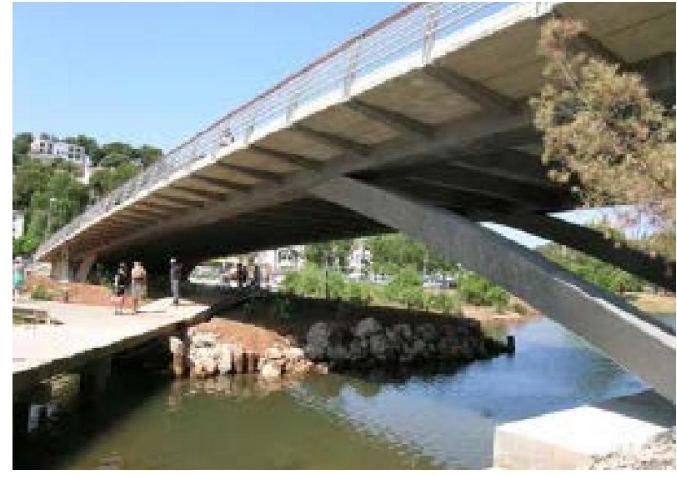

Slika 10. Podužni i poprečnim nosači

Lukovi imaju trougaoni presek i konstantnu visinu od $700 \mathrm{~mm}$ tokom cele svoje dužine. Međutim, širina varira od 700-1000 mm po sekcijijama. U centralnoj zoni mosta, lukovi se izdižu iznad nivoa podužnih glavnih nosača. Spreguta ploča je vertikalno povezana na dva, tako da poprečni presek je složen (Slike 5 i 9). Ovaj strukturni oblik omogućava direktan prenos vertikalnih opterećenja na uzdužne grede (pravougaoni šuplji profili od 1000 do $500 \mathrm{~mm}$, sa različitom debljinom u luku. [3]
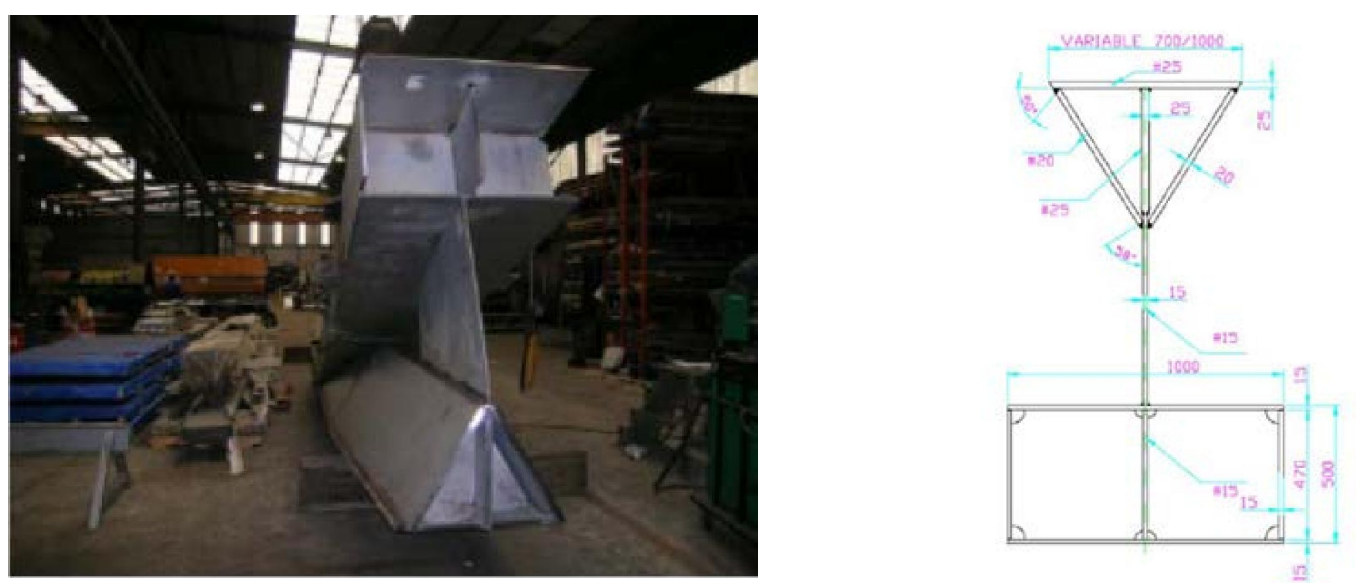

Slika 11. Ppoprečni presek dela luka mosta iznad kolovoza 
Poprečni nosači-grede su postavljene na rastojanju od $2 \mathrm{~m}$, su pravougaone šuplje sekcije $250 \mathrm{~mm}$ širine i dubine $500-570 \mathrm{~mm}$. Promenljive dimenzije poprečnih nosača omogućavaju da se postigne na kolovozu nagib od 2\%. Debljina elemenata varira između 10 i $12 \mathrm{~mm}$. Ovi poprečni nosači su povezani sa uzdužnim gredama ispod i na armirano betonskoj kolovoznu ploči iznad. Sprezanje gornjeg pojasa, koji ima prosečnu širinu nožice od $300 \mathrm{~mm}$ omogućeno je moždanicima prečnika $20 \mathrm{~mm}$ napravljenih od dupleks nerđajućeg čelika. Na slici br. 12 prikazan je podužni presek mosta a na slioci br.13 poprečni presek.

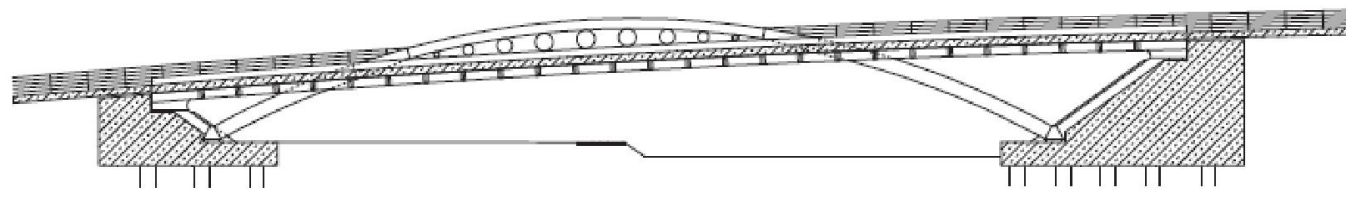

Slika 12. Podužni presek mosta

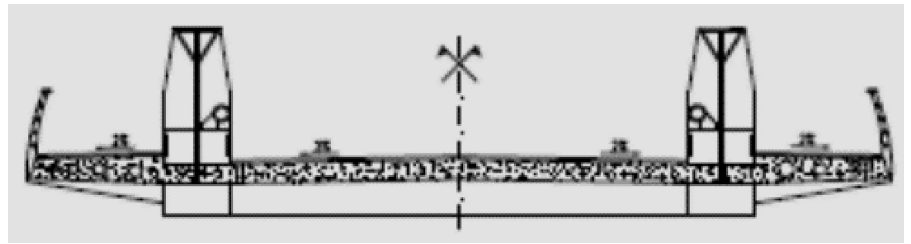

Slika 13. Poprečni presek mosta

Da se ne bi se prenela horizontalna komponenta aksijalne sile luka na potporne zidove, postavljeni su podupirači-kose grede(kosnici) koji povezuju oslonce podužnog nosača i luka. Podupirači su pravougaoni šuplji profili čije spoljašnje dimenzije su iste kao i uzdužne grede $(1000$ x $500 \mathrm{~mm})$, sa debljinama limova koje variraju između 20 i 25 $\mathrm{mm}$. Podupirači su interno nepomičnii u oba uzdužna i poprečnih pravaca. Jedan od najtežih delova mosta za projektovanje i izgradnju je bio veza između pravougaonog kosig podupiraču i trougaone preseka luka. Ova veza je napravljenqa korišćenjem visoko krutih oslonaca (slike 14 i 15) od čelika koji omogućava obrtanje oko jednog horizontalne ose.

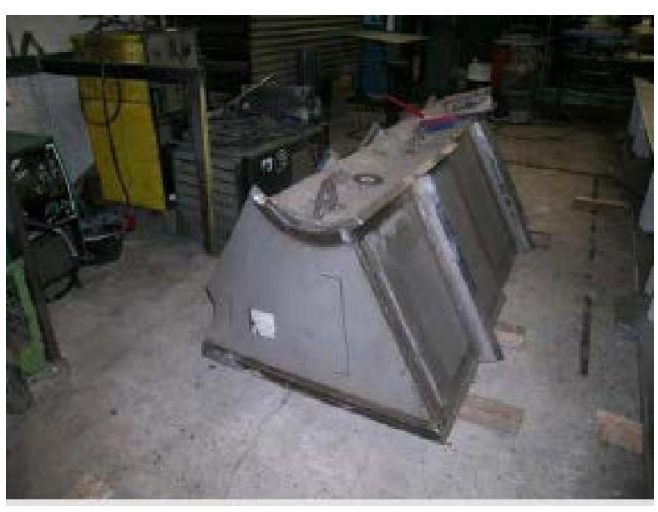

Slika 14. zavareni oslonački deo

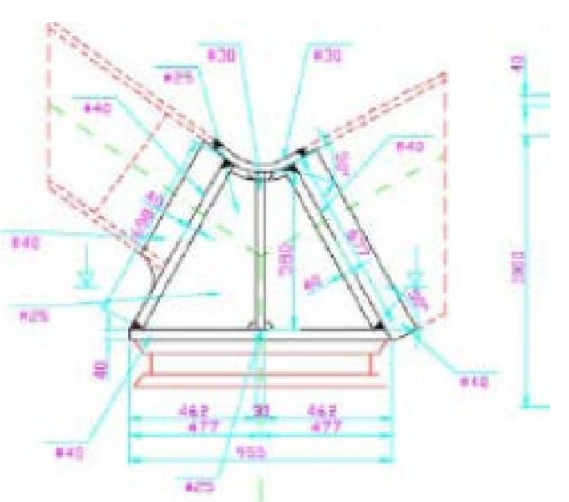

Slika 15. dimenzije poprečnog preseka

\section{4} | ZBORNIK RADOVA 22 (2013) | 


\section{i. Izrada i montaža}

Izrada obuhvata operacije sečenje ivica i priprema dupleks nerđajućeg čeličnih limova je sprovedena u Švedskoj, gde se proizvede ploče. Posle zavarivanja sa svih šavova su uklonjeni površinske naslage i nečistoće od oksida nastalih tokom zavarivanja. Montaža je morala obuhvatiti sve faze izvođenja, počev od rušenja postojećeg mosta, a izrada na novom mostu je počela u oktobru 2004 i završena je u junu 2005. Glavna konstrukcija od nerđajućeg čelika je sastavljena na licu mesta od 8 segmenata-delova. Svaki deo je bio podignut na privremene oslonace kako bi se olakšalo zavarivanje (Slika br.16). Moždanici za sprezanje su ručnio zavarivani (Slika 17). Prilikom zavarivanjem sprovedene su sve mere kontrole zavarivenih šavova, sprovedene standardnim metodama (vizuelni pregled, rendgen, magnetne metodom, itd). [4]

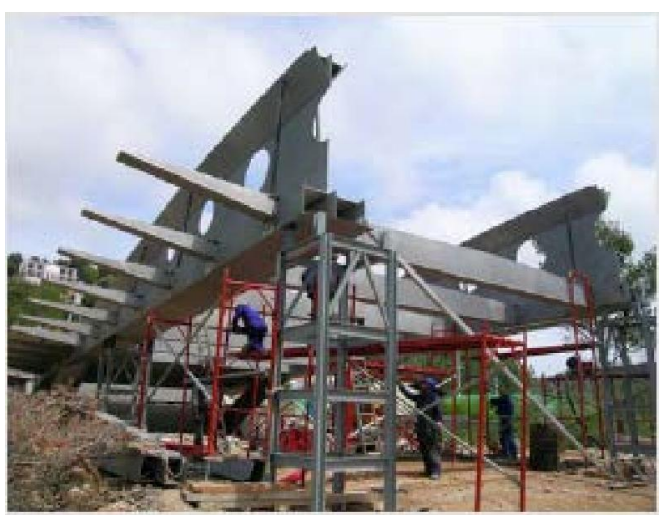

Slika 16. Montaža mosta

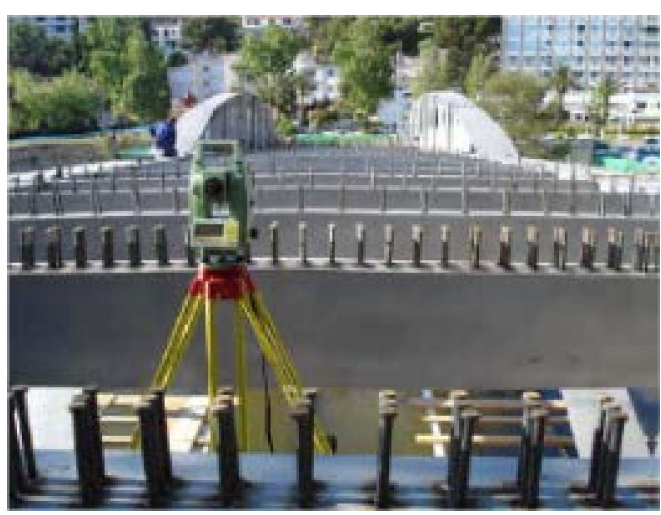

Slika 17. Izgled zavarenih moždanika

\section{SIJENA FOOTBRIDGE ( Sijena pešački most)}

Pešački most je statičkog sistema sa kosim kablovima, izveden je od nerđajućeg čelika, raspone preko $\mathrm{l}=60 \mathrm{~m}$, preko prometnog autoputa u predgrađu Ruffolo, Sijena, u centralnoj Italiji (završen je 2006. godine). Nosači mosta i stubovi su izrađeni od čistog dupleks nerđajućeg čelika prvi put korišćenog za neki pešačkog most. Most ima upečatljiv izgled, funkcionalnoje efikasan i ekonomičan sa niskim troškovima održavanja.

\subsection{Izbor materijala}

Konstrukcija mosta je morala obezbediti namanji vek odi 120 godina, bez velikih troškova za održavanjem. Projektanti su izabrali dupleks nerđajući čelika 1.4162 razred (S32101) za grede i stubova mosta. Ovi nerđajući dupleksi čelici imaju veoma nizak sadržaj nikla (1,5\% u poređenju sa $>3 \%$ u standardnim dupleks nerđajućim čelicima), što dovodi do značajne uštede u odnosu na druge austenitne i dupleks čelike. Usvojeni nerđajući čelik je klase 1,4162, ima veliku granicu razvlačenja (450 N/mm2),zatim dobru duktilnost (najmanje $30 \%$ ) i dobru obradivost i zavarivanje. Visoka čvrstoća omogućava smanjenje poprečnih preseka u odnosu da je most od ugljeničnih čelika. 


\subsection{Projektovanje}

Armirano-betonska kolovozna ploča je oslonjena na dva I $500 \mathrm{~mm}$ visoka podužna nosača (uzdužne grede), i međusobno je spregnuta. Poprečne nosači i konzole obezbeđuju na četiri mesta duž raspona vezu za ankere kosih kablova. Glavni nosači su izrađeni u obliki zavarenih I nosača sa vertikalnim ukrućenjima rebra da bi se sprečilo izbočavanje. Stubovi su kutijasti segmenti preseka, 400 x $600 \mathrm{~mm}$.

Oni su debljine 60 i $70 \mathrm{~mm}$, i povezani su sa zavarenim sidrima za glavne stubove. Sve delovi čelične noseće konstrukcije kao što su glavni nosači, poprečni nosači i stubovi su izvedeni od dupleks čelika, kvalitetnog čelika 1,4162. Na slici br.18 prikazan je deo glavnog podužnog i poprečnog nosača, a na slici br.19, izgled mosta.

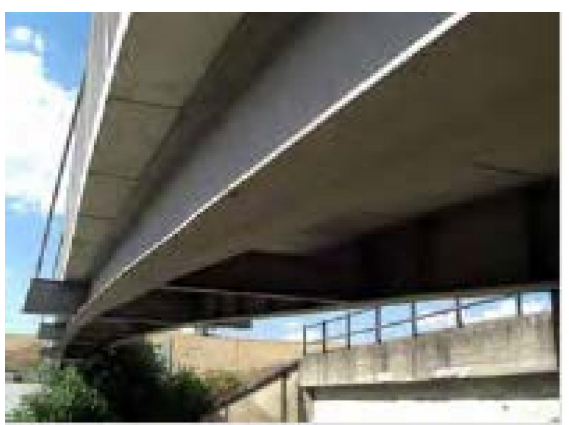

Slika 18. Izged podužnih i poprečnih nosača

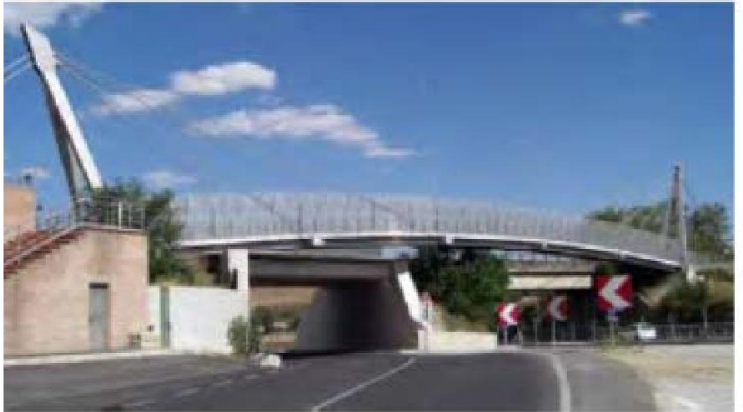

Slika 19. Izgled mosta sa pilonima

Most je širine $2 \mathrm{~m}$ i oslanjanjen je na svakih $12 \mathrm{~m}$. na kose kablove koje se sidre u konzole poprečnih nosača. Za formiranje glavnog podužnog nosača I poprečnog preseka korišćen je toplo valjani dupleks čelik nabavljen u Švedskoj, koji je transportovan u proizvodni centar u Solbiate Olona u Italiji. Ploče su tada plazmom sečene i ivice pripremljee za zavarivanje. Glavni podužni nosači i stubovi su proizvedeni u velikim delovima i onda isporučeni na mesto ugradnje. Stubovi-piloni i glavni podužni nosači su podizani na mesto kao jedna celina. Prefabrikovane armiranobetonske ploče su postavljene na glavne nosače sa već izvedenim moždanicima za spreuzanje. U pločama su ostavljani otvori-niše da bi se na licu mesta moglo izvesti betoniranje i tako omogućilo sprezanje kolovozne ploče sa čeličnim nosačima.

\section{LITERATURA}

[1] Бешевић М.: "Bearing capacity of cold formed high quality stainless steel members under end axial compresion“, IZGRADNJA 64 (2010) 7-8, 421-428

[2] Бешевић, М.: Прорачун аксијално притиснутих штапова према Еурокоду 3, Зборник радова Грађевинског факултета број 11, 1998, №. 11, стр. 9-20, УДК: 624.014:624-042, ИССН 0352-6852.

[3] ICET-2011, Thailand /Тешановић А., Бешевић М., Кукарас Д., Ландовић A.:"Influence of transversal slab bending on the composite action with steel girder", CE 5/191-194. 
[4] Nestorović Ž.,Trifković M., Bešević T. M., " On the possibilities of geodetic measurements utilization in construction dimensions control" Building Materijals and structures 1-vol 56 (2013) 1(51-62).

[5] EN 100088-4:2009 Stainless steels. Technical delivery conditions for sheet/plate and strip of corrosion resisting steels for construction purposes

[6] Practical guidelines for the fabrication of duplex stainless steels, International Molybdenum Association, 2001 (new Edition 2009)

\section{APPLICATION OF STAINLESS STEEL IN BRIDGE CONSTRUCTION}

Summary: Stainless steel is steel alloyed primarily with chromium and nickel. The term "stainless steel" is used for more than 120 different alloys with anti-corrosion properties. Stainless steels have a number of outstanding features that distinguish them from other classes of steel. Compared to carbon steel these features are, among other: non-alloy and asymmetric stress - strain behavior, anisotropy, pronounced response to cold forming process, different effects of initial imperfections, different thermal properties and therefore different distribution of residual stresses and their effects on the structure. Strength of stainless steel materials is usually assumed as proof strength at $0.2 \%$ strain, depending on the size of the plastic deformation and temperature at which it was exposed during production and usage. This paper shows the application of stainless steel in bridge construction (three bridges made of stainless steel).

Keywords: Stainless steel, mechanical properties, calculation, design, Eurocodes, bridges. 